Advances in Biological Research 1 (3-4): 92-98, 2007

ISSN 1992-0067

(C) IDOSI Publications, 2007

\title{
Effect of Soy Protein on Serum Lipid Profile and Some Lipid-metabolizing Enzymes in Cholesterol Fed Rats
}

\author{
${ }^{I}$ E. Chukwu Onyeneke, ${ }^{\prime}$ Olarewaju M. Oluba, ${ }^{2}$ Olalekan Adeyemi,

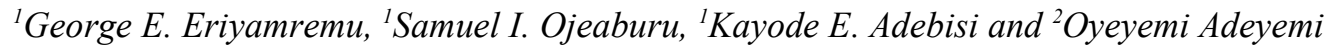

\author{
${ }^{1}$ Department of Biochemistry, University of Benin, P.M.B. 1154, Benin-City, Nigeria \\ ${ }^{2}$ Department of Biochemistry, Adekunle Ajasin University, P.M.B. 1, Akungba Akoko, Ondo State, Nigeria
}

\begin{abstract}
The effect of soy protein on serum lipid profile and some lipid metabolizing enzymes in rats fed with cholesterol diets was examined in this study. Rats were subjected to feeding trial over a period of six weeks on formulated diets containing: $20 \%$ soy protein with $0 \%$ cholesterol (group A); $20 \%$ soy protein with $5 \%$ cholesterol (group B), $20 \%$ soy protein with $10 \%$ cholesterol (group C), $0 \%$ soy protein with $20 \%$ cholesterol (group D) and 5\% soy protein with $20 \%$ cholesterol (group E). Serum total, VLDL, LDL and HDL-cholesterol and triglyceride concentrations were found to be reduced significantly in Groups B and C when compared with Groups $\mathrm{D}$ and $\mathrm{E}(\mathrm{p}<0.05)$. The lipid profile in group $\mathrm{C}$ did not however differ significantly when compared to the control group $(p>0.05)$. Groups D and E showed significant increase levels $(p<0.01)$ when compared to other groups. LPL, LCAT and TGL activities were found to be significantly reduced $(\mathrm{p}<0.05)$ in groups $\mathrm{B}$ and $\mathrm{C}$ when compared with groups D and E. Though groups B, C, D and E rats all showed significant elevation $(p<0.05)$ in the enzyme activities when compared to the control. This shows that soy protein intake improves serum lipid profile and hence may help reduce the incidence of sudden death from cardiovascular disease.
\end{abstract}

Key words: Soy protein $\cdot$ cholesterol $\cdot$ lipid metabolizing enzymes

\section{INTRODUCTION}

It is well known that cardiovascular disease (CVD) is the leading cause of death in both men and women in developed countries1. Hypercholesterolemia has been established as a primary risk factor in the development of CVD. Studies in this area are mostly preventive and have focused on ways of reducing serum cholesterol by nutritional means. Preventing or reducing the increase in serum cholesterol is associated with reducing risk for CVD. Diet plays an important role in controlling blood lipids. Although elevation of serum or tissue cholesterol after excessive cholesterol intake depends on the animal species, cholesterol administration has been shown to increase total cholesterol in rats [1]. The hypercholesterolemia that develops when animals are fed on high fat diet is consistently characterized by an increase in the molecular weight of serum low density lipoproteins (LDL) [2,3]. The hypercholesterolemic effect of soy protein has been recognized for more than thirty years [4]. Animal studies show that substituting soy protein for dietary animal protein reduces serum total and LDL cholesterol concentrations [5]. The magnitude of the cholesterol lowering effect of soy protein is similar to that observed for other plant-based foods such as oat bran, or garlic and has been confirmed to be a major clinical means of treating patients with genetically based hypercholesterolemia [6]. However, the real potential of soy protein appears to be preventing the rise in serum cholesterol which is diet-induced in almost $40 \%$ of the adult population and therefore in lowering the overall risk for CVD.

Changes in serum lipids are controlled by those enzymes responsible for lipid metabolism; Lipoprotein lipase (LPL) is the crucial enzyme in the metabolism of triglyceride rich lipoproteins. Elevated triglyceride rich lipoprotein levels not only may promote a more rapid progression of atherosclerosis, but could also lead to myocardial ischemia particularly in subjects with high triglyceride/low HDL traits which is frequently present in Coronary Artery Disease (CAD) [7]. Earlier reports have shown that sub endothelially located LPL

Corresponding Author: $\quad$ Dr. E. Chukwu Onyeneke, Department of Biochemistry, University of Benin, P.M.B. 1154, BeninCity, Nigeria 
exhibited proatherogenic effect by increasing oxidative susceptibility of LDL facilitating the uptake of triglyceride rich lipoproteins by macrophages [8]. The latter promotes foam cell formation [9] which is the hallmark of atherogenesis [10].

Lecithin: Cholesterol Acyl Transferase (LCAT) is a serum enzyme that esterifies free cholesterol, primarily at the surface of the HDL particle after which the cholesteryl ester molecules migrate to the inner core of this lipoprotein. Through this action, LCAT plays a key role in the maturation of HDL particles [11]. In humans, almost all serum cholesteryl esters are formed by the activity of $\operatorname{LCAT}[11,12]$ and individuals devoid of this enzyme show abnormal plasma lipoproteins [13]. Experimental findings have indicated that modification of serum proteins by LCAT alters rates of cholesterol flux between cells and medium and results in a net loss of cholesterol from the cells accompanied by cellular cholesterol synthesis [14-16]. Studies have shown that an increased activity of LCAT is proatherogenic [17, 18].

High levels of serum triglyceride has been strongly linked with low serum HDL cholesterol $[19,20]$ and these low HDL Levels may contribute to increased risk for CVD [21]. Triglyceride lipase is a major factor in the reduction of serum triglyceride concentration [22].

The enzymes: Lipoprotein lipase (LPL), LCAT and triglyceride lipase (TGL) have been hypothesized to participate in the regulation of cholesterol metabolism. This hypothesis coupled with the effect of soy protein on serum lipid profile is explored in this present study.

\section{MATERIALS AND METHODS}

Materials: All chemicals and reagents used were of analytical grade and are all products of either $\mathrm{BDH}$ Chemicals Limited, Poole, England or New England Nuclear Corp, Boston, MA, U.S.A.

Soy protein: Matured soy beans (uncooked) were purchased from Iwaro Market, Oka Akoko, Ondo State, Nigeria and was identified as Glycine maximus (soybean) by a taxonomist in the Department of Crop Science, Faculty of Agriculture, University of Benin, Nigeria. This was ground into powder and used in the diet formulation. Some of the soy protein was subsequently dropped at the herbarium of the faculty.

\begin{tabular}{lccccc}
\multicolumn{2}{l}{ Table 1: Feeding regimen for each group } \\
\hline Feed composition/groups & $\mathrm{A}$ & $\mathrm{B}$ & $\mathrm{C}$ & $\mathrm{D}$ & $\mathrm{E}$ \\
\hline Maize flour & 70 & 65 & 60 & 70 & 65 \\
Fish meal & 10 & 10 & 10 & 10 & 10 \\
Soy protein & 20 & 20 & 20 & - & 5 \\
Cholesterol & - & 5 & 10 & 20 & 20 \\
Total & 100 & 100 & 100 & 100 & 100 \\
Calorie equivalent & 450 & 475 & 500 & 510 & 530 \\
\hline
\end{tabular}

Animals and diets: Thirty five (35) twelve weeks old albino rats (Wistar Strain) weighing between 60-70 Kg purchased from the animal house of the department of Biochemistry, University of Ilorin, Nigeria were used for the study. The rats were housed in stainless steel cages with raised wire floors at a temperature of 30 degrees centigrade and fed on rat chow and water ad libidum for a period of two weeks to acclimatize. The animals were then divided into five groups of seven rats each designated A (control), B, C, D and E (experimentals) were then placed on five different dietary regimen as showed in Table 1. Before the commencement of the dietary regimen, the animals were fasted overnight but allowed access to water ad libitum. One rat from each group was sacrificed on Day 0 and each serum collected to determine the baseline level of the test parameters studied.

Serum preparation: At weekly intervals, one rat from each group was sacrificed and $2 \mathrm{ml}$ of blood was collected from the animal by cardiac puncture. The blood was allowed to stand at room temperature to clot and centrifuged at $10,000 \mathrm{~g}$ for 5minutes using Hettich (Universal II) centrifuge to separate serum from the cells. The supernatant (serum) was carefully decanted and analysis was carried out immediately.

Assays: Determination of total and free cholesterol in the serum was by the method of Searcy and Bergquist [23]. Serum triglyceride (TG) was determined using the method of Tiez [24] after enzymatic hydrolysis by lipases LDL and HDL-cholesterol were determined according to the methods described by Friedwald et al. [25] while VLDLcholesterol was calculated using Friedwald et al. [25] formular. Protein content was determined by the Biuret reaction [26] while lipoprotein lipase and triglyceride lipase activities were determined by the method of Kamimura et al. [27]. LCAT activity was determined by the methods described by Varma and Soloff [28]. Lipoprotein lipase and triglyceride lipase activity were measured in mmol of free fatty acids liberated per minute while LCAT activity was expressed in mg cholesterol ester formed per $100 \mathrm{ml}$ serum. 
Statistical analysis: Statistical analysis was done by one way analysis of variance (ANOVA) and Duncan Multiple range test (DMRT).

\section{RESULTS}

The animals consumed their daily rations satisfactorily and showed increase in their body weight. The weekly percentage increase in body weight for the respective groups is presented in Table 2 below.

Table 3 shows the weekly changes in serum total, free, esterified,VLDL-,LDL-, and HDL-cholesterol concentration observed for the respective groups over the six weeks treatment period.Results obtained indicate

Table 2: \% change in mean body weights

\begin{tabular}{|c|c|c|c|c|c|}
\hline \multirow[b]{2}{*}{ Time on diet (weeks) } & \multicolumn{5}{|c|}{ Groups } \\
\hline & A & $\mathrm{B}$ & $\mathrm{C}$ & $\mathrm{D}$ & $\mathrm{E}$ \\
\hline 0 & 0.00 & 0.00 & 0.00 & 0.00 & 0.00 \\
\hline 1 & 6.58 & 4.13 & 6.90 & 8.68 & 9.00 \\
\hline 2 & 8.38 & 14.57 & 11.59 & 13.15 & 9.06 \\
\hline 3 & 18.77 & 19.18 & 22.90 & 19.78 & 19.66 \\
\hline 4 & 25.33 & 20.54 & 23.82 & 35.75 & 30.80 \\
\hline 5 & 19.29 & 13.89 & 9.54 & 5.56 & 6.19 \\
\hline 6 & 14.58 & 14.41 & 12.39 & 11.90 & 6.25 \\
\hline
\end{tabular}

\begin{tabular}{|c|c|c|c|c|c|c|}
\hline \multirow{2}{*}{$\begin{array}{l}\text { Time on } \\
\text { diet (weeks) }\end{array}$} & \multicolumn{6}{|l|}{ Groups } \\
\hline & & A & B & $\mathrm{C}$ & D & E \\
\hline \multirow[t]{6}{*}{0} & $\mathrm{TC}$ & $197.0 \pm 2.0^{\mathrm{aa}}$ & $193.3 \pm 3.0^{\mathrm{a}}$ & $198.3 \pm 6.0^{\mathrm{a}}$ & $195.3 \pm 4.0^{\mathrm{a}}$ & $197.0 \pm 4.0^{\mathrm{a}}$ \\
\hline & VLDL-C & $19.7 \pm 0.8^{\mathrm{a}}$ & $19.3 \pm 0.8^{\mathrm{a}}$ & $19.8 \pm 0.5^{\mathrm{a}}$ & $19.5 \pm 0.6^{\mathrm{a}}$ & $19.7 \pm 0.7^{\mathrm{a}}$ \\
\hline & LDL-C & $128.3 \pm 3.0^{\mathrm{a}}$ & $126.0 \pm 4.0^{\mathrm{a}}$ & $129.0 \pm 4.0^{\mathrm{a}}$ & $127.0 \pm 2.0^{\mathrm{a}}$ & $128.0 \pm 3.0^{\mathrm{a}}$ \\
\hline & HDL-C & $49.0 \pm 1.0^{\mathrm{a}}$ & $48.0 \pm 2.0^{\mathrm{a}}$ & $49.5 \pm 1.0^{\mathrm{a}}$ & $48.8 \pm 1.0^{\mathrm{a}}$ & $49.3 \pm 1.0^{\mathrm{a}}$ \\
\hline & $\mathrm{FC}$ & $65.0 \pm 1.0 \mathrm{a}$ & $64.3 \pm 2.0 \mathrm{a}$ & $66.3 \pm 2.0 \mathrm{a}$ & $65.3 \pm 2.0 \mathrm{a}$ & $66.0 \pm 2.0 \mathrm{a}$ \\
\hline & $\mathrm{CE}$ & $132.0 \pm 3.0 \mathrm{a}$ & $129.0 \pm 2.0 \mathrm{a}$ & $132.0 \pm 3.0 \mathrm{a}$ & $130.0 \pm 2.0$ & $131.0 \pm 1.0 \mathrm{a}$ \\
\hline \multirow[t]{6}{*}{1} & $\mathrm{TC}$ & $195.5 \pm 3.0^{\mathrm{a}}$ & $192.2 \pm 1.0^{\mathrm{a}}$ & $199.0 \pm 3.0^{\mathrm{b}}$ & $200.0 \pm 4.0^{b}$ & $199.0 \pm 3.0^{\mathrm{b}}$ \\
\hline & VLDL-C & $19.5 \pm 0.9^{\mathrm{a}}$ & $19.2 \pm 0.6^{\mathrm{a}}$ & $20.9 \pm 0.5^{\mathrm{a}}$ & $20.0 \pm 0.4^{\mathrm{a}}$ & $19.9 \pm 0.5^{\text {a }}$ \\
\hline & LDL-C & $127.0 \pm 3.0^{\mathrm{a}}$ & $125.0 \pm 3.0^{\mathrm{a}}$ & $129.9 \pm 2.0^{\mathrm{a}}$ & $130.0 \pm 3.0^{\mathrm{a}}$ & $129.3 \pm 2.0^{\mathrm{a}}$ \\
\hline & HDL-C & $49.0 \pm 2.0^{\mathrm{a}}$ & $48.0 \pm 1.0^{\mathrm{a}}$ & $47.2 \pm 3.0^{\mathrm{a}}$ & $50.0 \pm 2.0^{\mathrm{a}}$ & $49.8 \pm 2.0^{\mathrm{a}}$ \\
\hline & $\mathrm{FC}$ & $64.5 \pm 2.0 \mathrm{a}$ & $64.2 \pm 3.0 \mathrm{a}$ & $66.0 \pm 2.0 \mathrm{a}$ & $67.0 \pm 2.0 \mathrm{a}$ & $66.0 \pm 2.0 \mathrm{a}$ \\
\hline & $\mathrm{EC}$ & $131.0 \pm 2.0 \mathrm{a}$ & $128.0 \pm 3.0 \mathrm{a}$ & $133.0 \pm 2.0 \mathrm{a}$ & $133.0 \pm 2.0 \mathrm{a}$ & $133.0 \pm 3.0 \mathrm{a}$ \\
\hline \multirow[t]{6}{*}{2} & $\mathrm{TC}$ & $193.3 \pm 3.0^{\mathrm{a}}$ & $190.7 \pm 2.0^{b}$ & $192.2 \pm 3.0^{\mathrm{b}}$ & $207.5 \pm 5.0^{\mathrm{c}}$ & $204.4 \pm 3.0^{\mathrm{c}}$ \\
\hline & VLDL-C & $19.3 \pm 1.2^{\mathrm{a}}$ & $19.2 \pm 0.8^{\mathrm{a}}$ & $19.2 \pm 0.6^{\mathrm{a}}$ & $20.7 \pm 0.7^{\mathrm{a}}$ & $20.4 \pm 0.5^{\mathrm{a}}$ \\
\hline & LDL-C & $126.0 \pm 1.0^{\mathrm{a}}$ & $124.0 \pm 2.0^{\mathrm{a}}$ & $125.0 \pm 3.0^{\mathrm{a}}$ & $135.0 \pm 2.0^{\mathrm{b}}$ & $133.0 \pm 2.0^{\mathrm{b}}$ \\
\hline & HDL-C & $48.0 \pm 3.0^{\mathrm{a}}$ & $47.5 \pm 1.0^{\mathrm{a}}$ & $48.0 \pm 2.0^{\mathrm{ab}}$ & $51.8 \pm 1.0^{\mathrm{b}}$ & $51.0 \pm 2.0^{\mathrm{b}}$ \\
\hline & $\mathrm{FC}$ & $64.3 \pm 3.0 \mathrm{a}$ & $63.7 \pm 3.0 \mathrm{a}$ & $64.2 \pm 1.0 \mathrm{a}$ & $69.5 \pm 3.0 \mathrm{a}$ & $68.4 \pm 2.0 \mathrm{a}$ \\
\hline & $\mathrm{EC}$ & $129.0 \pm 1.0 \mathrm{a}$ & $127.0 \pm 2.0 \mathrm{a}$ & $128.0 \pm 3.0 \mathrm{a}$ & $138.0 \pm 2.0 \mathrm{a}$ & $136.0 \pm 2.0 \mathrm{a}$ \\
\hline \multirow[t]{6}{*}{3} & $\mathrm{TC}$ & $198.8 \pm 2.0^{\mathrm{a}}$ & $190.9 \pm 3.0^{b}$ & $193.5 \pm 3.0^{\mathrm{b}}$ & $221.7 \pm 4.0^{\mathrm{c}}$ & $213.9 \pm 5.0^{\mathrm{d}}$ \\
\hline & VLDL-C & $19.8 \pm 0.6^{\mathrm{a}}$ & $19.1 \pm 0.6^{\mathrm{a}}$ & $19.3 \pm 0.4^{\mathrm{a}}$ & $22.2 \pm 0.8^{b}$ & $21.0 \pm 0.8^{b}$ \\
\hline & LDL-C & $129.0 \pm 3.0^{\mathrm{a}}$ & $124.0 \pm 1.0^{\mathrm{b}}$ & $126.0 \pm 1.0^{\mathrm{ab}}$ & $144.0 \pm 2.0^{\mathrm{c}}$ & $139.0 \pm 1.0^{\mathrm{d}}$ \\
\hline & HDL-C & $50.0 \pm 3.0^{\mathrm{a}}$ & $47.8 \pm 0.5^{\mathrm{a}}$ & $48.2 \pm 1.2^{\mathrm{a}}$ & $55.5 \pm 0.5^{b}$ & $53.5 \pm 1.0^{b c}$ \\
\hline & $\mathrm{FC}$ & $66.8 \pm 1.0 \mathrm{a}$ & $64.9 \pm 2.0 \mathrm{a}$ & $64.5 \pm 2.0 \mathrm{a}$ & $74.7 \pm 2.0 \mathrm{~b}$ & $71.0 \pm 4.0 \mathrm{~b}$ \\
\hline & $\mathrm{EC}$ & $132.0 \pm 2.0 \mathrm{a}$ & $127.0 \pm 2.0 \mathrm{~b}$ & $129.0 \pm 2.0 \mathrm{ab}$ & $148.0 \pm 3.0 \mathrm{c}$ & $143.0 \pm 4.0 \mathrm{c}$ \\
\hline \multirow[t]{6}{*}{4} & $\mathrm{TC}$ & $195.6 \pm 3.0^{\mathrm{a}}$ & $189.1 \pm 4.0^{b}$ & $195.6 \pm 2.0^{\mathrm{a}}$ & $246.1 \pm 8.0^{\mathrm{c}}$ & $229.2 \pm 7.0^{\mathrm{d}}$ \\
\hline & VLDL-C & $19.6 \pm 0.2^{\mathrm{a}}$ & $18.9 \pm 0.5^{\mathrm{a}}$ & $19.6 \pm 0.6^{\mathrm{a}}$ & $24.6 \pm 0.6^{b}$ & $22.9 \pm 0.9^{\mathrm{c}}$ \\
\hline & LDL-C & $127.0 \pm 2.0^{\mathrm{a}}$ & $123.0 \pm 2.0^{\mathrm{b}}$ & $127.0 \pm 1.0^{\mathrm{a}}$ & $160.0 \pm 3.0^{\mathrm{c}}$ & $149.0 \pm 1.0^{\mathrm{d}}$ \\
\hline & HDL-C & $49.0 \pm 1.0^{\mathrm{a}}$ & $47.2 \pm 2.0^{\mathrm{a}}$ & $49.0 \pm 1.0^{\mathrm{a}}$ & $61.5 \pm 2.0^{\mathrm{b}}$ & $57.3 \pm 2.0^{\mathrm{b}}$ \\
\hline & $\mathrm{FC}$ & $65.0 \pm 2.0 \mathrm{a}$ & $63.0 \pm 3.0 \mathrm{a}$ & $65.0 \pm 4.0 \mathrm{a}$ & $82.0 \pm 3.0 \mathrm{~b}$ & $76.0 \pm 3.0$ \\
\hline & $\mathrm{EC}$ & $131.0 \pm 1.0 \mathrm{a}$ & $126.0 \pm 2.0 \mathrm{~b}$ & $131.0 \pm 2.0 \mathrm{a}$ & $164.0 \pm 4.0 \mathrm{c}$ & $153.0 \pm 3.0 \mathrm{~d}$ \\
\hline \multirow[t]{6}{*}{5} & $\mathrm{TC}$ & $198.9 \pm 4.0^{\mathrm{a}}$ & $189.1 \pm 1.0^{b}$ & $196.9 \pm 3.0^{\mathrm{a}}$ & $253.9 \pm 9.0^{\mathrm{c}}$ & $237.0 \pm 6.0^{\mathrm{d}}$ \\
\hline & VLDL-C & $19.8 \pm 0.1^{\mathrm{a}}$ & $18.9 \pm 0.4^{b}$ & $19.7 \pm 0.3^{\mathrm{a}}$ & $25.4 \pm 0.7^{\mathrm{c}}$ & $23.7 \pm 0.5^{\mathrm{d}}$ \\
\hline & LDL-C & $129.0 \pm 2.0^{\mathrm{a}}$ & $123.0 \pm 1.0^{\mathrm{b}}$ & $128.0 \pm 2.0^{\mathrm{a}}$ & $165.0 \pm 4.0^{\mathrm{c}}$ & $154.0 \pm 1.0^{\mathrm{d}}$ \\
\hline & HDL-C & $50.0 \pm 1.0^{\mathrm{a}}$ & $47.2 \pm 2.0^{\mathrm{a}}$ & $49.2 \pm 0.5^{\mathrm{a}}$ & $63.5 \pm 1.0^{\mathrm{b}}$ & $59.3 \pm 1.0^{\mathrm{c}}$ \\
\hline & $\mathrm{FC}$ & $66.0 \pm 1.0 \mathrm{a}$ & $63.0 \pm 2.0 \mathrm{~b}$ & $66.0 \pm 1.0 \mathrm{a}$ & $85.0 \pm 2.0 \mathrm{c}$ & $79.0 \pm 2.0 \mathrm{~d}$ \\
\hline & $\mathrm{EC}$ & $132.0 \pm 2.0 \mathrm{a}$ & $126.0 \pm 1.0 \mathrm{~b}$ & $131.0 \pm 3.0 \mathrm{a}$ & $169.0 \pm 5.0 \mathrm{c}$ & $158.0 \pm 3.0$ \\
\hline \multirow[t]{6}{*}{6} & $\mathrm{TC}$ & $198.8 \pm 3.0^{\mathrm{a}}$ & $187.5 \pm 3.0^{\mathrm{b}}$ & $195.6 \pm 2.0^{\mathrm{a}}$ & $267.5 \pm 4.0^{\mathrm{c}}$ & $258.3 \pm 3.0^{\mathrm{d}}$ \\
\hline & VLDL-C & $19.8 \pm 0.3^{\mathrm{a}}$ & $18.7 \pm 0.5^{b}$ & $19.6 \pm 0.4^{\mathrm{a}}$ & $26.7 \pm 0.5^{\mathrm{c}}$ & $25.8 \pm 0.6^{\mathrm{d}}$ \\
\hline & LDL-C & $129.0 \pm 1.0^{\mathrm{a}}$ & $122.0 \pm 2.0^{\mathrm{b}}$ & $127.0 \pm 3^{\mathrm{a}}$ & $174.0 \pm 1.0^{\mathrm{c}}$ & $168.0 \pm 2.0^{\mathrm{d}}$ \\
\hline & HDL-C & $50.0 \pm 1.0^{\mathrm{a}}$ & $46.8 \pm 0.5^{b}$ & $49.0 \pm 1.0^{\mathrm{a}}$ & $66.8 \pm 1.0^{\mathrm{c}}$ & $64.5 \pm 1.0^{\mathrm{c}}$ \\
\hline & $\mathrm{FC}$ & $66.0 \pm 1.0 \mathrm{a}$ & $62.0 \pm 1.0 \mathrm{~b}$ & $65.0 \pm 2.0 \mathrm{a}$ & $89.0 \pm 1.0 \mathrm{c}$ & $86.0 \pm 2.0 \mathrm{~d}$ \\
\hline & $\mathrm{EC}$ & $132.0 \pm 1.0 \mathrm{a}$ & $125.0 \pm 3.0 \mathrm{~b}$ & $131.0 \pm 2.0 \mathrm{a}$ & $178.0 \pm 3.0 \mathrm{c}$ & $172.0 \pm 3.0 \mathrm{c}$ \\
\hline
\end{tabular}

Tabulated results are means of five determinations \pm SEM. Values in the same row carrying different superscripts are significantly different $(\mathrm{p}<0.05)$

TC: Total cholesterol; VLDL-C: Very low density lipoprotein cholesterol; LDL-C: Low density lipoprotein cholesterol;HDL-C: High density lipoprotein cholesterol; FC: Free cholesterol; EC: Esterefied cholesterol 
Table 4: Serum triglycerides concentration $\left(\mathrm{mg} \mathrm{dl}^{-1}\right)$

\begin{tabular}{lccccc}
\hline $\begin{array}{l}\text { Time on diet } \\
\text { (weeks) }\end{array}$ & A & B & C & D & E \\
\hline 0 & $134 \pm 2^{\text {a }}$ & $131 \pm 3^{\text {a }}$ & $137 \pm 5^{\text {a }}$ & $136 \pm 3^{\text {a }}$ & $133 \pm 3^{\text {a }}$ \\
1 & $137 \pm 4^{\text {a }}$ & $135 \pm 2^{\text {a }}$ & $138 \pm 4^{\text {a }}$ & $150 \pm 3^{\text {b }}$ & $146 \pm 2^{\mathrm{b}}$ \\
2 & $139 \pm 3^{\text {a }}$ & $137 \pm 2^{\text {b }}$ & $142 \pm 3^{\mathrm{b}}$ & $168 \pm 5^{\mathrm{c}}$ & $160 \pm 3^{\mathrm{c}}$ \\
3 & $138 \pm 2^{\mathrm{a}}$ & $141 \pm 2^{\mathrm{a}}$ & $140 \pm 3^{\mathrm{a}}$ & $189 \pm 4^{\mathrm{b}}$ & $181 \pm 3^{\mathrm{c}}$ \\
4 & $140 \pm 3^{\mathrm{a}}$ & $143 \pm 2^{\mathrm{a}}$ & $143 \pm 2^{\mathrm{a}}$ & $206 \pm 9^{\mathrm{b}}$ & $209 \pm 7^{\mathrm{b}}$ \\
5 & $143 \pm 4^{\mathrm{a}}$ & $146 \pm 2^{\mathrm{a}}$ & $144 \pm 3^{\mathrm{a}}$ & $220 \pm 6^{\mathrm{b}}$ & $222 \pm 5^{\mathrm{b}}$ \\
6 & $144 \pm 3^{\mathrm{a}}$ & $148 \pm 2^{\mathrm{a}}$ & $146 \pm 2^{\mathrm{a}}$ & $233 \pm 7^{\mathrm{b}}$ & $237 \pm 5^{\mathrm{b}}$ \\
\hline
\end{tabular}

Tabulated results are means of five determinations \pm SEM. Values in the same row carrying different superscripts are significantly different $(\mathrm{p}<0.05)$

Table 5: Serum lipoprotein lipase $\left(\mathrm{mmol} / \mathrm{min} \times 10^{-2}\right)$

\begin{tabular}{lccccc}
\hline $\begin{array}{l}\text { Time on diet } \\
\text { (weeks) }\end{array}$ & $\mathrm{A}$ & $\mathrm{B}$ & $\mathrm{C}$ & $\mathrm{D}$ & $\mathrm{E}$ \\
\hline 0 & $8 \pm 0.4^{\mathrm{a}}$ & $9 \pm 0.8^{\mathrm{a}}$ & $8 \pm 0.5^{\mathrm{a}}$ & $8 \pm 0.3^{\mathrm{a}}$ & $9 \pm 1.0^{\mathrm{a}}$ \\
1 & $10 \pm 1.0^{\mathrm{a}}$ & $12 \pm 0.9^{\mathrm{b}}$ & $11 \pm 0.5^{\mathrm{b}}$ & $23 \pm 2.0^{\mathrm{c}}$ & $22 \pm 2.0^{\mathrm{c}}$ \\
2 & $11 \pm 2.0^{\mathrm{a}}$ & $13 \pm 1.0^{\mathrm{a}}$ & $15 \pm 2.0^{\mathrm{a}}$ & $25 \pm 2.0^{\mathrm{b}}$ & $26 \pm 2.2^{\mathrm{b}}$ \\
3 & $14 \pm 1.4^{\mathrm{a}}$ & $20 \pm 2.0^{\mathrm{b}}$ & $21 \pm 1.3^{\mathrm{b}}$ & $32 \pm 2.0^{\mathrm{c}}$ & $30 \pm 1.4^{\mathrm{c}}$ \\
4 & $13 \pm 1.6^{\mathrm{a}}$ & $25 \pm 3.1^{\mathrm{b}}$ & $28 \pm 2.6^{\mathrm{b}}$ & $37 \pm 2.3^{\mathrm{c}}$ & $33 \pm 1.7^{\mathrm{c}}$ \\
5 & $11 \pm 0.9^{\mathrm{a}}$ & $16 \pm 0.8^{\mathrm{b}}$ & $17 \pm 1.4^{\mathrm{b}}$ & $22 \pm 1.8^{\mathrm{c}}$ & $20 \pm 2.0^{\mathrm{c}}$ \\
6 & $9 \pm 0.8^{\mathrm{a}}$ & $15 \pm 1.5^{\mathrm{b}}$ & $16 \pm 1.0^{\mathrm{b}}$ & $20 \pm 2.0^{\mathrm{c}}$ & $17 \pm 1.3^{\mathrm{c}}$ \\
\hline
\end{tabular}

Tabulated results are means of five determinations \pm SEM. Values in the same row carrying different superscripts are significantly different $(\mathrm{p}<0.05)$

Table 6: Serum (LCAT) activity (mg cholesterol ester/100ml serum)

\begin{tabular}{lccccc}
\hline $\begin{array}{l}\text { Time on diet } \\
\text { (weeks) }\end{array}$ & $\mathrm{A}$ & $\mathrm{B}$ & $\mathrm{C}$ & $\mathrm{D}$ & $\mathrm{E}$ \\
\hline 0 & $58.5 \pm 2.0^{\mathrm{a}}$ & $58.0 \pm 2.0^{\mathrm{a}}$ & $58.0 \pm 2.0^{\mathrm{a}}$ & $58.0 \pm 2.0^{\mathrm{a}}$ & $58.0 \pm 2.0^{\mathrm{a}}$ \\
1 & $61.0 \pm 3.0^{\mathrm{a}}$ & $93.5 \pm 3.0^{\mathrm{b}}$ & $89.0 \pm 4.0^{\mathrm{b}}$ & $101.5 \pm 6.0^{\mathrm{c}}$ & $115.0 \pm 4.0^{\mathrm{d}}$ \\
2 & $58.0 \pm 6.0^{\mathrm{a}}$ & $117.5 \pm 7.0^{\mathrm{b}}$ & $115.5 \pm 5.0^{\mathrm{b}}$ & $120.5 \pm 3.0^{\mathrm{b}}$ & $118.0 \pm 2.0^{\mathrm{b}}$ \\
3 & $57.0 \pm 1.0^{\mathrm{a}}$ & $121.0 \pm 2.0^{\mathrm{b}}$ & $119.0 \pm 3.0^{\mathrm{b}}$ & $155.0 \pm 6.0^{\mathrm{c}}$ & $137.0 \pm 3.0^{\mathrm{d}}$ \\
4 & $58.5 \pm 2.0^{\mathrm{a}}$ & $132.5 \pm 4.0^{\mathrm{b}}$ & $130.0 \pm 2.0^{\mathrm{b}}$ & $160.5 \pm 1.0^{\mathrm{c}}$ & $152.0 \pm 2.0^{\mathrm{d}}$ \\
5 & $60.5 \pm 1.0^{\mathrm{a}}$ & $140.5 \pm 3.0^{\mathrm{b}}$ & $139.5 \pm 2.0^{\mathrm{b}}$ & $163.5 \pm 0.5^{\mathrm{c}}$ & $154.5 \pm 1.0^{\mathrm{d}}$ \\
6 & $61.5 \pm 0.8^{\mathrm{a}}$ & $142.5 \pm 0.6^{\mathrm{b}}$ & $141.0 \pm 0.3^{\mathrm{b}}$ & $170.5 \pm 1.0^{\mathrm{c}}$ & $157.5 \pm 0.6^{\mathrm{d}}$ \\
\hline \multicolumn{5}{l}{ Tabulated results are means of five determinations \pm SEM. Values in the same } \\
row carrying different superscripts are significantly different $(\mathrm{p}<0.05)$
\end{tabular}

Table 7: Serum Triglyceride lipase activity $\left(\mathrm{mmol} / \mathrm{min} \times 10^{-2}\right)$

\begin{tabular}{lccccc}
\hline $\begin{array}{l}\text { Time on diet } \\
\text { (weeks) }\end{array}$ & A & B & C & D & E \\
\hline 0 & $9 \pm 0.8^{\mathrm{a}}$ & $9 \pm 1.2^{\mathrm{a}}$ & $9 \pm 0.5^{\mathrm{a}}$ & $9 \pm 1.3^{\mathrm{a}}$ & $9 \pm 0.8^{\mathrm{a}}$ \\
1 & $10 \pm 1.2^{\mathrm{a}}$ & $12 \pm 1.6^{\mathrm{a}}$ & $11 \pm 1.8^{\mathrm{a}}$ & $19 \pm 1.5^{\mathrm{b}}$ & $17 \pm 2.0^{\mathrm{b}}$ \\
2 & $12 \pm 0.6^{\mathrm{a}}$ & $17 \pm 1.9^{\mathrm{b}}$ & $15 \pm 2.0^{\mathrm{b}}$ & $25 \pm 3.1^{\mathrm{c}}$ & $21 \pm 0.7^{\mathrm{d}}$ \\
3 & $14 \pm 1.2^{\mathrm{a}}$ & $23 \pm 2.0^{\mathrm{b}}$ & $22 \pm 2.2^{\mathrm{b}}$ & $33 \pm 3.4^{\mathrm{c}}$ & $29 \pm 1.4^{\mathrm{d}}$ \\
4 & $17 \pm 2.2^{\mathrm{a}}$ & $28 \pm 1.2^{\mathrm{b}}$ & $25 \pm 2.6^{\mathrm{b}}$ & $35 \pm 1.2^{\mathrm{c}}$ & $32 \pm 2.0^{\mathrm{c}}$ \\
5 & $12 \pm 0.8^{\mathrm{a}}$ & $17 \pm 1.5^{\mathrm{b}}$ & $16 \pm 1.4^{\mathrm{b}}$ & $29 \pm 2.1^{\mathrm{c}}$ & $27 \pm 1.8^{\mathrm{c}}$ \\
6 & $11 \pm 1.2^{\mathrm{a}}$ & $13 \pm 2.0^{\mathrm{b}}$ & $13 \pm 1.6^{\mathrm{b}}$ & $24 \pm 2.2^{\mathrm{c}}$ & $22 \pm 1.3^{\mathrm{c}}$ \\
\hline
\end{tabular}

Tabulated results are means of five determinations \pm SEM. Values in the same row carrying different superscripts are significantly different $(\mathrm{p}<0.05)$ that rats in groups B and C fed $20 \%$ soy protein with $5 \%$ and $10 \%$ cholesterol respectively showed decreases in their serum cholesterol levels when compared to the control while groups D and E rats fed 20\% cholesterol with 0 and $5 \%$ soy protein respectively showed significant increases $(\mathrm{p}<0.05, \mathrm{p}<0.01)$ in their serum cholesterol levels when compared to the control and groups B and C. Generally, the reduction in group B rats was statistically significant $(p<0.05)$ when compared to the control and in all the cholesterol fractions. Group $\mathrm{E}$ $(5 \%$ soy protein $+20 \%$ cholesterol) rats however had reduced cholesterol fraction levels $(\mathrm{p}<0.05)$ when compared to group D rats $(0 \%$ soy protein $+20 \%$ cholesterol).

Table 4 shows the changes in the serum triglyceride concentration for the respective groups studied. Although there was no significant mean difference in group B and C rats ( $>0.05)$, group D rats fed $20 \%$ cholesterol without soy protein showed significantly elevated levels of serum triglyceride $(\mathrm{p}<0.05)$.

Table 5 shows lipoprotein lipase activity (expressed in mmol of free fatty acid hydrolysed per minute) for the respective groups over the six week period. Rats in groups B, C, D and E showed a significant increase $(p<0.05)$ in their serum lipoprotein lipase activity when compared to the control. The enzyme activity in group D is about 2-folds that of the control and inclusion of soy protein showed significant reduction $(\mathrm{p}<0.05)$ in the activity of LPL when compared to group $\mathrm{D}$ rats.

The esterifying activity of serum LCAT expressed as $\mathrm{mg}$ cholesterol ester formed per $100 \mathrm{ml}$ serum is as shown in Table 6. The results obtained showed that rats in groups D and E fed $20 \%$ cholesterol with $0 \%$ soy protein and $5 \%$ soy protein respectively showed about 3-fold and 2.5-fold respectively increase in activity when compared to the control rat at the end of the feeding trial. Though rats in groups B, C, D and E showed a significant increase $(p<0.05)$ in LCAT activity when compared with the control, higher activity was observed in group D when compared with groups $\mathrm{B}$ and $\mathrm{C}$.

Table 7 shows the results obtained for serum triglyceride lipase (TGL) activity for the respective groups. At the end of the feeding trial rats in group D showed elevated levels in serum triglyceride lipase (TGL) $(p<0.01)$ when compared comparedto the control.The groups on soy protein supplementation (groups B and C) showed significantl reduction $(\mathrm{p}<0.05)$ in TGL levels when compared to group D $(0 \%$ soy protein $+20 \%$ cholesterol $)$. 


\section{DISCUSSION}

Cholesterol rich diet has been demonstrated by several workers to increase serum total, VLDL and LDLcholesterol as well as serum triglyceride concentrations $[3,18,29]$. Contrary to the expected elevation of serum total cholesterol, VLDL cholesterol, LDL cholesterol and triglyceride concentrations, the results obtained from this study show decreased total VLDL and LDL cholesterol as well as triglyceride concentrations. The results obtained for groups $\mathrm{B}$ and $\mathrm{C}$ rats showed reductions in their serum total, VLDL and LDL cholesterol concentration as well as triglyceride concentrations. This could be attributable to the inclusion of $20 \%$ soy protein in the animal diet. This observation is justifiable since group D rats fed diet containing no soy protein showed significantly $(p<0.05)$ raised levels serum total cholesterol, VLDL cholesterol, LDL cholesterol and triglyceride concentrations, while group E rats fed diet containing $5 \%$ soy protein showed significant decrease $(p<0.05)$ in their serum total, VLDL and LDL cholesterol concentration as well as triglyceride concentrations when compared group D rats. This results further strengthens the earlier reports on the hypocholesterolemic effect of soy protein $[4,5]$.

Comparative clinical trials by Anderson et al. [30], showed than consumption of diets rich in soy protein as opposed to those high in animal protein significantly lowers blood total cholesterol level, LDL cholesterol and triglycerides without lowering helpful HDL cholesterol. Kirk et al. [31] have also demonstrated that diet containing intact or unextracted soy protein significantly reduces lesion areas in wild type mice when compared to those fed phytooestrogen extracted soy protein 31 . They equally observed that there was no difference in the extent of atherosclerosis in the LDL receptor deficient mice fed intact soy protein and those fed phytoestrogen extracted soy protein. This suggests that cellular LDL receptors play a significant role in soy protein hypocholesterolemic effect [32]. The activities of lipid metabolizing enzymes especially lipoprotein lipase, LCAT and triglyceride lipase have been reported to be responsive to nutritional factors [19, 33]. Exogenous cholesterol does contribute significantly in the regulation of the activities of these enzymes. Hypertriglyceridemia, a major risk factor for CVD has been demonstrated to be associated with increased LPL and TGL activity $[19,22,34]$. Similarly, variation in the serum level of HDL cholesterol has been reportedly linked to the activity of LPL and TGL [19, 20, 34]. Low levels of HDL cholesterol observed in patients at high risk of CVD have been associated with increased LPL and TGL activities. The result of our present study shows that consumption of soy protein reduces to baseline levels serum LPL and TGL activity. Earlier reports by Onyeneke et al. [18] and Ononugbu et al. [17] have demonstrated that increased LCAT activity is proatherogenic. The results obtained from this study supports this claim, This is justified since group D rats fed diets containing 0\% soy protein with $20 \%$ cholesterol showed significantly higher LCAT activity when compared with group B and $\mathrm{C}$ rats fed $20 \%$ soy protein. The action of soy protein on the activity of these lipid metabolizing enzymes could be attributable to its hypocholesterolemic effect. Thus, reduction in serum levels of cholesterol and triglycerides may lead to a corresponding decrease in the activity of these enzymes. It is therefore suggested that the inclusion of soy protein in the diet improves serum lipid profile as well as control the activities of the lipid metabolizing enzymes. Hence, soy protein will be beneficial in reducing the increased risk to and consequent death (resulting from intake of high fat diet) due to atherosclerosis.

\section{REFERENCES}

1. Kummerow, F.A., 1982. The possible involvement of dietary fats in atherosclerosis. Prog. Lipid Res., 21: 743-746.

2. Vegroesen, A.J., 1972. Dietary fat and cardiovascular disease: Possible modes of action of linoleic acid. Proc. Nutri. Soc., 31: 323-329.

3. Berg, K.A., H. Borrensen and G. Dahlen, 1986. Serum hydro-density lipoproteins and atherosclerotic heart diseases. Lancet, 1: 499-501.

4. Carroll, K.K. and E.M. Kurowska, 1995. Soy consumption and cholesterol reduction: review of animal and human studies. J. Nutr., 125: 5945-5975.

5. Wangen, K., A. Duncan, $\mathrm{X}$. $\mathrm{Xu}$, et al. 2001. Soy isoflavins improves plasma lipids in normocholesterolemic and mildly hypercholesterolemic post menopausal women. Am. J. Clin Nutr., 73: 225-231.

6. Setchell, K.D., 1998. Phytoestrogens: the biochemistry, physiology and implications for human health of soy isoflavins. Am. J. Clin. Nutr., Dec; 68 (6 suppl): S1333-1346. 
7. Nordis, H.N. and W.J. Mack, 1995. Triglyceride-rich lipoproteins and progression of coronary artery disease. Curr. Opin. Lipidol., 6: 209-214.

8. Milosavjevic, D., A. Kontush, S. Griglio, G. Le Naour, J. Thrillet and M.J. chapman, 2003. VLDL-induced triglyceride accumulation in human macrophages is mediated by modulation of LPL lipolytic activity in the absence of change in LPL mass. Biochin Biophys Acta, 1631: 51-60.

9. Babaev, V.R., S. Fazio, L.A. Gleaves, K.J. Carter, C.F. Semenkovich and M.F. Linton, 1999. Macrophage lipoprotein lipase promotes foam cell formation and atherosclerosis in vivo. J. Clin. Invest., 103: 697-705.

10. Libby, P., P.M. Ridker and A. Maseri, 2002. Inflammation and atherosclerosis. Circulation, 105: 1135 .

11. Glomset, J.A., 1968. The Plasma Lecithin: Cholesterol acyl transferase reaction. J. Lipid Res., 9: 155-167.

12. Nordby, G. and K.R. Norum, 1975. Substrate specificity of lecithin: cholesterol acyl transferase, esterification of demosterol, â-sitosterol and cholecalciferol in human plasma. Scand. J. Clin. Lab. Invest., 35: 677-682.

13. Glomset, J.A., K.R., Norum and W. King, 1970. Plasma lipoproteins in familial lecithin: cholesterol acyl transferase deficiency: lipid composition and reactivity in vitro. J. Clin Invest., 49: 1827-1937.

14. Glomset, J.A., 1976. Lecithin: cholesterol acyl transferase in lipoprotein metabolism, ed. By Greton, H; Springer-Verlag, Berlin, New York, pp: 28-41.

15. Ray, E., F. Bellini, G. Stoudt, S. Hemperly and G. Rothblat, 1980. Influence of lecithin: cholesterol acyl transferase on cholesterol metabolism in hepatoma cells and hepatocytes. Biochim Biophys Acta, 617: 318-334.

16. Relimpio, A. and A.J. Iriarte, 1981. Re-evaluation of cholesterol homeostasis and atherosclerosis. J. Biol. Chem., 256: 4478-4488.

17. Ononriogbu, I.C. and G.C. Okpara, 1986. Effect of garri diet on lecithin: cholesterol acyl transferase, Nutr. Rep. Intl., 33: 19-87.

18. Onyeneke, E.C., E.O. Alumanah and I.C. Ononogbu, 1991. Changes in plasma lecithin: cholesterol acyl transferase activity in rats fed on cholesterol diet. J. Clin. Biochem Nutr., 10: 27-34.
19. Richards, E.G., S.M. Grundy and K. Cooper, 1989. Influence of plasma triglycerides on lipoprotein patterns in normal subjects and in patients with coronary artery disease. Am. J. Cardiol., 63: 1214-1220.

20. Avogaro, P., G. Ghiselli, S. Soldan and G. Bittolo Bon, 1991. Relationship of triglycerides and HDL cholesterol in hypertriglceridemia. Atherosclerosis., 92: 79-86.

21. Assman, G., H. Schulte, W. Oberwittler and W.H. Hause, 1986. New aspects in the prediction of coronary artery disease: the prospective cardiovascular monster study. In: Fidge, N.H. and P.J. Nestel, (Eds). Atherosclerosis VII. Amsterdam, Netherlands: Elsevier Science Publishers. 19-24.

22. Kanter, M.A., A. Bianchini, D. Bernier, S.P. Sady and P.D. Thompson, 1985. Androgen reduce $\mathrm{HDL}_{2}{ }^{-}$ cholesterol and increase hepatic triglyceride lipase activity. Med-Sci Sports Exercise. 17: 462-465.

23. Searcy, R.L. and L.M. Berquist, 1960. A new colour reaction for the quantification of serum cholesterol. Clin. Chim. Acta, 5: 192-199.

24. Tiez, N.W., 1990. Clinical guide to laboratory tests. $2^{\text {nd }}$ edn. W.B. Saundrs company, Philadelphia, U.S.A. 554.

25. Friedwald, W.T., R.T. Levy and D.S. Fredickson, 1972. Estimation of the concentration of low density lipoprotein cholesterol in plasma, without use of preparative ultracentrifuge. Clin. Chem., 18: 499-502.

26. Gurnall, A.G., C.T., Bardawill and M.M. David, 1949. Determination of serum protein by means of biuret reaction. J. Biol. Chem., 177: 751-766.

27. Kamimura, E.S., O. Mendieta, H.H. Sato, G. Pastore and F. Maugeri, 1999. Production of lipase from Geotricum $s p$ and adsorption studies on affinity resin. Braz. J. Chem. Eng, Vol: 16.

28. Varman, K.G. and L.A. Soloff, 1976. A method for the purification of milligram quantities of stable human phosphatidyl choline-cholesterol acyl transferase. Biochem. J., 155: 583-599.

29. McGill, H.C. Jr 1998. The pathogenesis of atherosclerosis. Clin. Chem., 34: B33-B39.

30. Anderson, J.W., B.M. Johnstone and M.E. CookNewell, 1995. Meta-analysis of the effects of soy protein intake on serum lipids. N. Engl. J. Med. Aug., 3: 276-282. 
31. Kirk, E.A., P. Sutherland, S.A. Wang, A. Chait and R.C. LeBaeuf, 1998. Dietary isoflavines reduce plasma cholesterol and atherogenesis in C57BL/6 mice but not LDL receptor-deficient mice. J. Nutr., 128: 954-959.

32. Baum, J.A., H. Teng, J.W. Erdman Jr; R.M. Weigel, B.P. Klein, V.W. Persky, S. Freels, P. Surya, R.M. Bakhit, E. Ramos, N.F. Shay and S.M. Potter, 1998. Long term intake of soy protein improves blood lipid profiles and increases mpononuclear cell low density lipoprotein receptor messenger RNA in hypercholesterolemic, post menopausal women. Am. J. Clin Nutr. Sep., 68: 545-551.
33. Fielding, C.J. and P.E. Fielding, 1980. Characteristic of triacylglycerol and partial acylglycerol hydrolysis by human plasma lipoprotein lipase. Biochim Biophys. Acta., 620: 440-446.

34. Patsch, W. and A.M. Gotto, Jr, 1995. High density lipoprotein cholesterol, plasma triglyceride and coronary heart disease. Pathophysiology and management. Adv. Pharmacol., 32: 375-426. 